\section{Families of children with Down syndrome}

\section{Cliff. C. Cunningham}

\author{
Visiting Professor of Applied Psychology \\ School of Health \\ Liverpool John Moores University
}

Introduction

This paper focuses on two key questions:

1. What is the effect of having a child with Down syndrome on the family? - How does the child effect the way they function as a system? What factors put them at risk and conversely, what factors provide resilience to potential stressors?

2. What is the effect of the family on the child? - in other words what factors positively or negatively influence the development and well-being of the child?

I will be mainly using the research results, coloured by my own experiences, from the Manchester Down syndrome Cohort Study which I started in 1973. I have been fortunate in being able to follow over 100 families over the years and the last project, completed by my colleagues Sloper and Turner (1994) investigated them in the teenage years. Currently we are visiting them again as they enter adulthood.

I will begin by briefly describing the cohort and the families, and the background to the various studies we have made.

\section{Background}

In order to give an overview of the key findings I will have to leave out detailed descriptions of methodology. These can be found in the references listed. We have used an extensive range of measures based on both qualitative and quantitative methods. All the research reported has been subject to critical peer review and published in refereed journals or project reports.

I would like to emphasise that we view the family as a transactional system in which many variables are constantly interacting on each other and changing. To cope with this dynamic system we have used multivariate approaches in an attempt to identify the most influential factors associated with stability and change over time that influence family wellbeing. But beyond this we are also seeking to describe a style of how families deal with life circumstances that increases or decreases the chances of well being (Rutter 1989).

If one is to do this it is essential that the sample is representative of the population of families of children with Down syndrome.

\section{The cohort}

Between 1973 and 1980 we were notified of 203 births. Twenty-two families did not join the project because the babies died, were placed out of the area in care or parents moved or did not reply to our invitation. One hundred and eighty one families joined the project which represents between 85 and $90 \%$ of all births of infants with Down syndrome in the area during this period.

The families did not differ from similar families in Britain at this time with the exception that there was a small bias toward more non-manual and more educated and financially betteroff families. This has been found in other cohorts of families of children with Down syndrome ( e.g. Carr 1988). Also, the average age of parents was slightly older as would be expected given the increased incidence of births to older mothers. Thus the cohort included some teenage mothers and single parent families, families from ethnic minorities
(C) 1993, 1999. The Down Syndrome Educational Trust Down Syndrome Research and Practice 1996, 4 (3) 87-95 
and second marriages. Some were rich and some were very poor. Some had large extended families and some small nuclear families.

This is to be expected as the incidence of Down syndrome is largely the same across different races and cultures. The point to be emphasised is that the families with a child with Down syndrome are no different to other families when the child is born and exhibit the same large individual differences. There is not, therefore, a typical type of family of a child with Down syndrome.

The children with Down syndrome also show a wide range of individual differences in terms of their cognitive, social and physical abilities, health status and personality. For example we found IQ scores in the pre-school years ranged from less than 20 to 100 with a mean around 50. Carr (1988) reported similar ranges in the early years and when she followed up her cohort at 21 years of age the IQ's ranged from less than 20 to 70 , with a mean of 40 . It is worth noting that this range covers some $60 \mathrm{IQ}$ points which is similar to the variance found for the 'normal' population. We also found a wide range of differences in temperament in the early childhood years (Gibbs 1984) similar to that found in normal distributions but with more children showing a dampened and passive personality and over $70 \%$ being relatively easy to manage and interact with. However 25 to $30 \%$ had difficult temperaments, tended to be restless and excitable and were difficult to manage.

A problem with longitudinal studies is that individuals are lost over time. In our cohort we had 134 families when the children were five years old. The attrition during this period was due to deaths and families moving away. No parent had dropped out of the study. In our last study in 1991 we had contact with 118 families and 106 took part in the study. The fall in numbers was again largely due to families moving and some deaths. However several have refused to take part in later studies for many reasons. Therefore we carefully examined how representative the current cohort is compared with our original group at each follow-up. Over the years the proportion of single parent families has increased from 4 to $15 \%$ which compares to $20 \%$ in the general population. We also have fewer mothers in employment compared with the general population - a finding reported in many studies of children with disability. So far we have not found any significant differences on major variables for the follow-up studies and feel reasonably confident that we have representative findings.

\section{The studies}

There have been five major studies over the years. The first was the early development and intervention study (19731982). We visited all families at least every six weeks and gave them structured programmes to stimulate their infant and discussed any problems. We collected demographic data, developmental assessments of the child and descriptive information of the children's health and problems experienced by the families. The second study (1982) obtained mother's perceptions about family adaptation and functioning using interviews and we measured maternal stress and child behaviour problems. In 1984-85, the third study examined the long-term effects of the early intervention and behaviour problems in the cohort compared to a comparison group (these studies are reported in detail in Byrne et al 1988, Cunningham 1987). The fourth study in
1986-88 was a much more detailed multivariate study of family adaptation which included information from fathers and was repeated five years later in 1991 when the children were in their teenage years. This study also included information from the siblings for the first time.

\section{Theoretical focus}

Early research on families of children with disability reflected a pathological model in that families were automatically assumed to suffer as a consequence of the child - in effect the studies only looked for negative outcomes (Byrne and Cunningham 1985). We adopted a transactional family system model and combined this with the Folkman and Lazerus (1985) cognitive theory of stress and coping. This approach argues that any event, such as the disability of a family member, will have different meanings and effects for each individual and that only the individual can appraise whether the effect is distressful. The potential effect of such an event will be modified by the availability and use of resources and coping strategies. Resources include 1) physical - health, energy and stamina, 2) utilitarian finances, housing, employment, 3) social - social networks and support systems, 4) psychological - belief systems, problem solving skills, personality. Lack of resources to cope with a situation are likely to increase strain or stress on the family situation. Hence they constitute a need (Cunningham and Davis 1985). Coping strategies refer to how parents try to deal with problems and reduce the strain or stress they cause. They can be focused on emotion or practical problems. Strategies range from passive e.g. wishful thinking (hoping the problem will go away), stoical (making light of the problem), through to active strategies e.g. problem solving. If the stressful situation is resolved the person is more likely to feel strong and in control, which can then strengthen their coping resources for the future. If not resolved this places a chronic burden on resources and may lead to negative effects on physiological and psychological well-being.

Thus our approach has been to assess an extensive range of factors that might have negative or positive effects on the family and child with Down syndrome.

Child measures include: mental ability using developmental and IQ tests, self-sufficiency indicating degree of personal, domestic and social independent living skills, social life encompassing friendships and use of leisure time, behaviour problems, and academic attainments. These are the main outcome measures but we also measured a number of descriptor variables: gender, age, position in family, health problems, temperament on the dimension of excitabilitydistractibility, supervision and caretaking needs, intensity of early intervention and type of school attended.

The two main outcome measures used to assess parents were distress, using a 24 item checklist of psychosomatic symptoms, and satisfaction with life, based on an index of how mothers and fathers felt about their life in general, social support, time for self, life with partner and other family members, finances and parenting. Parents also completed a number of validated scales about their personality, locus of control, marital relationships, social support, contact with services and perceived satisfaction with services. To investigate family functioning, parents completed the Family Environment Scale (Moos and Moos 1981) and the Family Relations Index (Holahan and Moos 1983). Parent-child 
relationships and attachment were assessed from interview. In addition they also completed a Life-events scale and the ways of Coping Questionnaire (Folkman and Lazerus 1985) adapted for the families of children with Down syndrome (Knussen et al 1992). The demographic variables measured were social class, unemployment, parent educational level, housing, car ownership, marital status, age of parent, size of family, financial problems.

\section{What are the effects of having a child with Down syndrome on the family}

The weight of evidence from all the studies is that the majority of the families (65-70\%) function like most families and are not 'at risk' because of the child's Down syndrome. They did not show above thresholds of psychological and physiological distress and the scores were lower when compared with studies of families of children with other disabilities (Quine and Pahl 1989, Sloper and Turner 1993). On the family functioning measures they exhibited good internal relationships, cohesion and expressiveness. Mink et al. (1983) reported that $68 \%$ of their families with children with Down syndrome were rated as cohesive and harmonious and had significantly higher morale than families of children with other intellectual disabilities. Three-quarters of our families were consistently rated over the years for positive expressions of warmth and affection toward their child with Down syndrome. The divorce rate in the cohort has always been lower than the national average and only $14 \%$ felt that having a child with Down syndrome had had a detrimental effect on their marriage. Hence the majority of families report good marital relationships. This has also been recently reported for an Australian sample (Cuskelly and Dodds 1992). In 1984 and 1991 we asked mothers about the effects of having a child with Down syndrome on themselves and the family. Less than a third thought there had been detrimental effects. The majority felt there were no real detrimental effects and usually responded that they had changed for the better. Typically they felt they were less concerned with trivia, less materialistic and self-centred. Their comments indicate a shift in beliefs to more pro-social behaviour. They also felt their partners and other children had benefited in the same way. Mink et al. (1983) speculated that the higher morale in families of children with Down syndrome could be because of a positive effect of the child on the home climate.

Thus the picture, in childhood, is that the child with Down syndrome is not a burden and mere recipient of family care for most families. In fact they appear to make a positive contribution.

By the teenage years, a decrease was found in mothers' perceived satisfaction with life. This was associated with a decline in actual and perceived satisfaction with social support. There was also a trend for more mothers to perceive negative effects of the child with Down syndrome on the family. It would appear that they felt their teenager with Down syndrome was placing greater restrictions on family life compared to a non-disabled teenager. In the 'normal' family life-cycle most parents experience more independence as the children reach the teenage years and become more independent. But this does not happen for the majority of teenagers with Down syndrome. Their slower development and learning disabilities forces them to get out of step with the normal life cycle. Depending on their level of ability, skills and interests, they begin to have fewer social contacts and friends who are not disabled. By the teenage years many are relatively isolated and become increasingly dependent on the family for social interaction. As one father succinctly described it "I have become the entertainment organiser for my son". The greater the supervision needs of the child the greater the restrictions on the family. For example, we found that the level of behaviour problems in the children was significantly related to reduced social contacts, friendships and increased ratings of negative effects on the family.

\section{Potential risk factors}

Between a quarter and a third of the families were experiencing difficulties. This was reflected in higher levels of measured distress and lower satisfaction with life. The longitudinal analysis showed that the strongest predictor of any measure in the teenage years was the score on that measure five years earlier. For example, the measure of stress for mothers was particularly stable over the 9 years from early childhood to the teenage.

This is important as it indicates that the pattern of family and child functioning becomes relatively well established in the childhood years. The implication is that any intervention to change the pattern must focus on the early years.

For mothers and fathers the factor most associated with negative stress was behaviour problems in the child. For the majority of families the management of the child became easier as they got older and this was associated with increases in self-sufficiency and reduced behaviour problems. Despite this, the level of behaviour problems found in the early childhood years strongly predicted later levels and the scores became increasingly stable from the mid-childhood to the teenage years. The children most likely to have significant behaviour problems had lower mental ability and suffered from repeated infections and health problems in the childhood years. Studies have shown that behaviour problems are more likely in children with prolonged hospitalisation, chronic ill-health and injury. The suggestion is that such events increase strain on the family and can also alter child management methods and expectations of child functioning. This can lead to increased over-protection by parents and increased dependency for the children. If this occurs in families with relationship problems the effect is compounded. We found that behaviour problems in the sibling were significantly associated with poor family relationship patterns but not with any characteristics of the child with Down syndrome.

Fathers of children with low IQ, with or without behaviour problems, and more so if the child was a boy, consistently reported lower satisfaction with life over the years. This supports the suggestion, commonly reported in the literature and by mothers, that fathers are more likely to have problems of adaptation. The recent longitudinal study over the first years of life by Shonkoff et al. (1992) found that fathers continually reported higher levels of stress than mothers in their attachment to the child and that these levels were higher for fathers of children with Down syndrome compared to other disabilities. Thus many fathers may find they are less fulfilled in their parenting role because their child has Down syndrome. This may reflect their problems in coming to terms with having such a child.

It is possible, however, that these increased problems are not just about male pride and ego. Early intervention efforts frequently focus on mothers because fathers are often at 
work during contact time. Thus fathers receive less support. Hence we must make efforts to meet fathers individual needs. In my experience this is not easy as many fathers are reluctant to attend meetings or seek counseling. However in the weeks following the birth many parents are in a high state of uncertainty and are actively seeking guidance. I find this an opportune time to establish relationships which, if they are perceived by mothers and fathers to be helpful, can last over the years. Within this, one has an opportunity to overcome male resistance and possibly help with problems of adaptation. But this has to be a well formulated individual approach.

Thus low functioning and behaviour problems which occur in less than a third of the children with Down syndrome is a risk factor for family well-being. However even when the child is functioning at this level it is not inevitable that the families experience the same levels of stress or low satisfaction. The effects of these characteristics on well being are modified by the family resources. Our results show three important groups: social-economic, personality and family relationship variables.

Family well-being was associated with lack of utilitarian resources, rather than social class status. For example inadequate housing predicted levels of behaviour problems and through this parental stress. Financial problems and lack of a car was associated with mothers' stress levels and poorer family relationships. If both parents were employed mothers reported less strain and more satisfaction. Those mothers in employment had lower stress scores than those who were unemployed and this was independent of previous stress scores. Thus it appears that by the later childhood and teenage years employment outside the home had some protective effect for mothers' well being. This may be because they have more social contacts and access to support, respite from the demands of the home and child, alternative interests and the chance to appraise their situation with people outside of the family.

Unfortunately, compared with national figures, the mothers of children with disabilities are less likely to be in employment. Presumably this is because of the care needs of their child. However we found in the early studies those from our cohort were more likely to be employed than a comparison group. We felt this was a result of the support and encouragement we gave to seek employment rather than just feeling they had to be with the child because of the disability. Even so, $40 \%$ of the mothers in the later studies stated that the child's disability restricted their own employment opportunities. This was often related to the need for after school and holiday care which for some children needed to be specialized. Given the potential effect of mother employment on family finances, housing and general well being, and through this the child's development and quality of life, the provision of services assisting their employment would appear to be a worthwhile endeavor.

The personality of parents was measured on the dimension of neuroticism. The number having relatively high levels was no greater than expected for the general population. Detail analysis indicated that high neuroticism in parents indicated a personal vulnerability to stressors and higher stress scores. Higher neuroticism scores were also associated with higher levels of child behaviour problems. However when the parent had the resources of social support and used practical problem solving strategies to cope, the potential effects of neuroticism on levels of stress and child functioning were reduced. This suggests the potential of interventions for these families in developing their social support and practical coping mechanisms.

Not surprisingly family relationships emerge as an important resource affecting all members. Strong and direct associations were found between satisfaction with life scores and positive marital and parent-child relationships. Like any child, those children with Down syndrome in cohesive and harmonious families were also less likely to have behaviour problems and more likely to have higher levels of functioning.

Mothers expressing poor relationships with the child and family were more likely to have high stress scores. Poor child relationships were likely when the child with Down syndrome had a difficult temperament -high excitability- and these children were also more likely to be in the lower IQ range and, over time, to develop more behaviour problems. Mothers were also more likely to express family problems if they were experiencing financial problems. No other variable was significant. Thus early assessment indicating difficult temperament and low ability in the child should led to interventions aimed at establishing a more positive parentchild relationship. When financial problems are apparent, specific financial support and advice on money management may also avoid the likelihood of deterioration in relationships. For these families help aimed at these issues would appear to be more cost-effective than child centred interventions helping to promote quicker development. Indeed it is these families who are more likely to be unable to comply with the demands of many early intervention programmes (Cunningham 1985).

The third aspect that emerged was the use of coping strategies.

Fathers' use of stoicism when appraising child problems was significantly associated with higher satisfaction with life scores in mothers. It appeared that those fathers who made light of the situation and refused to take it too seriously provided some support for mothers who tended to have a more emotional reaction. Clearly there is a sensitive balance in the interrelationships of parents and one can imagine conflict resulting from fathers who persistently ignore or make light of serious problems effecting the mother.

The strongest coping strategy to emerge was wishful thinking. When used to cope with child problems there was a significant negative effect on the well-being of mothers and fathers. It is not an effective strategy because it is unlikely to resolve the problem which remains as a stressor. In a proportion of the families wishful thinking remained dominant over the five year period from childhood to teenage. However there was an indication that it became less influential with an increase in passive acceptance of problems. It is as if 'hope' that things will improve gives way to 'acceptance' and the family increasingly adopts a routine of passive style of coping. This is often seen with families of young adults with Down syndrome, even in cohesive families who have worked hard and positively for their child. They fall into easy, less stressful routines and the young person is incorporated into the life-style of the parents. In such families the child and young adult is also more likely to adopt a passive personal coping style, i.e. learned helplessness. 
These factors were also associated with parental external locus of control i.e. feeling that one had little control over one's life. A link was also found between neuroticism and wishful thinking. Parents with higher neuroticism scores were more likely to adopt the strategy of wishful thinking, which being ineffectual, leads to distress. A recent review (Knussen and Sloper 1992) of studies using the resource and coping strategy model outlined earlier, concluded that families of children with learning difficulties most at risk had children with behaviour problems, reduced resources in finances and materials (e.g. cars, washing machines etc.); inadequate social support and personality and belief systems (e.g. neuroticism, low self-esteem); were more likely to use fewer problem-solving and more passive emotion-focused ways of coping, particularly wishful thinking.

In contrast we found that families who used problem solving strategies appeared to score more highly on variables associated with well-being. Moreover, such strategies were associated with higher functioning in the child with Down syndrome.

Thus there is good support for the idea that interventions should focus on helping those families at risk for passive coping mechanisms who are likely to show poor psychological resources, external locus of control and possible neuroticism. Zeitlin et al $(1986,1987)$ have described such an approach and its application to a small scale intervention. Recently Kirkham (1993) demonstrated that mothers of young children with disability who received such intervention improved in their coping and communications and reported less depression and higher satisfaction with life than a control group. This persisted over a two year period following the training programme.

Although such approaches need to be used in the early years this type of support may need to be offered in later years especially for those families who may be gradually developing more passive and less expectant approaches.

\section{Siblings}

Research on siblings of children with disabilities presents a confused picture with conflicting results often due to methodological problems.

One approach has tried to investigate if the siblings are more at risk for emotional and behavioural problems. These have reported more aggression in siblings (Lobato et al 1987); more behaviour problems in younger brothers (Breslau et al 1981), brothers (Gath and Gumley, 1987) and older sisters (Gath 1973, Breslau et al 1981, Cuskelly and Dodds 1992, Cuskelly and Gunn 1993) and no effects on sisters (Gath and Gumley 1987) and no negative effects on siblings (Carr and Hewett 1982).

A second approach has tried to investigate the roles and responsibilities of siblings possibly associated with parental demands and higher expectations due to some form of compensatory mechanism. Again the studies are equivocal. McHale and Gamble (1989) found that siblings report more caregiving than comparison children but Cuskelly and Gunn (1993) found no differences. No support was found for the suggestion that parents have higher expectations of the nondisabled child.

In the 1991 study, there were 63 siblings living at home and over 10 years in our cohort. They were interviewed about their views of having a brother or sister with Down syndrome, their roles and responsibilities and relationships with the family. They completed self report questionnaires on selfworth, anxiety and their perceived support and regard from their parents. Mothers completed a scale of sibling behavioural problems. The analysis examined these measures in combination with the measures on family functioning and characteristics of the child with Down syndrome.

The main finding was of positive adaptation. Around $80 \%$ of the siblings stated they had a positive relationships with their parents and their sibling with Down syndrome and a positive or neutral effect of having a brother or sister with Down syndrome. They also had positive perceptions of their own self-worth. 95\% were actively involved in helping roles with their sibling. There was no indication of any detrimental effect and, in fact, the helping role was more strongly associated with positive relationships with their sibling with Down syndrome. Sixty percent felt they did not take on more household responsibility than their peers whilst $21 \%$ felt they did more and $19 \%$ felt they did the same amount.

As with our previous results the majority of mothers felt that having a brother or sister with Down syndrome had had a positive effect on their other children. This was seen in achievements and increased pro-social behaviour. Again, many mothers felt that the care needs of the child with Down syndrome had reduced the opportunities for family leisure time and the siblings own time for themselves.

A complex picture emerged for $20 \%$ showing signs of poorer adaptation. No effect was found for age or older sisters being at risk. Eighteen percent of the siblings were rated with above threshold on behaviour problems but this was not significantly related to any characteristic of the child with Down syndrome. As found in our earlier studies the main factor associated with behaviour problems was family relationships. Within this all variables associated with mothers' adaptation but not fathers' adaptation were significant. This highlights the significant role mothers play in fostering family relationships. There was an indication of lower levels of behaviour problems in siblings for those fathers who used social support as a coping mechanism to deal with problems associated with their child with Down syndrome. Thus it appears that the behaviour problems of the child with Down syndrome is not the main factor affecting sibling problems. Of course it may be that where the behavioural problems of the child with Down syndrome effect family relationships and particularly mothers adaptation and coping this in turn influenced family relationships and then sibling behaviour. But the siblings are not at risk if there are sufficient resources to cope with such behaviour - for example the use of the social networks and support by both parents. They take their view of the sibling with Down syndrome from their parents.

The minority of siblings with low self-worth scores had brothers and sisters with Down syndrome who had lower self-sufficiency scores and so placed higher demands on family resources and restrictions on activities. These siblings were also more likely to have higher trait anxiety scores and lower perceived support and regard from their parents. This may reflect problems in parental expectations and demands upon the sibling. Some felt that their brother or sister with Down syndrome was a burden on their own lives and these 
siblings also had higher behaviour problems. Many were also more likely to have perceived themselves as different to their peers in the amount of help they gave with caretaking activities - either more or less. Most teenagers use social comparison processes in the development of self-concept and self-worth. Conformity with the peer group is an important part of this. Thus these siblings might perceive that their families were different and, by association, they were different.

It would appear, therefore, that there is a small group of siblings at risk, especially if the child with Down syndrome has low self-sufficiency skills thus requiring more caretaking and supervision, are of an anxious disposition, feel they receive low levels of parental support and encouragement, the sibling with Down syndrome is a burden and they or their families are different. Within this complex there are numerous explanatory mechanisms. The risk to these siblings is reduced when families have the resources to balance the needs of the all members and take a positive view of each other. For those in families that are somewhat insular and isolated, possibly due to the demands of the less independent child with Down syndrome, there is a risk that they perceive themselves as different and develop lower self-worth. Mothers are strongly influential but there are indications that fathers can play a significant role to counter act the demands placed on mothers of the child with Down syndrome and this is more likely when fathers use their social support network. Clearly these issues require more thorough investigation before we can develop interventions.

\section{Factors associated with the development of the child with Down syndrome}

I will describe the factors associated with the outcome measures of developmental age and mental ability, attainments (academic and self-sufficiency), behaviour problems and social life.

\section{Mental ability and early development:}

In the first three years of life children with severe health (mainly heart) problems made slower physical progress but no effect was found for mental ability. Early intervention and intense structured training during the first two years of life had an immediate small impact on the targeted behaviours but no generalised or long term effects and the main predictor of later scores was earlier scores on the same test - although this was modest in the first year or so. These findings are similar to those reported in other studies (e.g. Gibson and Field, 1988; Shonkoff et al., 1992).

From around two years of age - mental ages of around 18 24 months - significant associations appeared between mental age scores and social class and educational level of parents - with the latter showing the strongest influence. By 4 to 5 years the girls had higher mean group scores than the boys. This is the same pattern as is found for ordinary children.

From around the second to third year of life the mental ability scores on the children became increasing stable with correlations falling in the 0.7 to 0.9 range. Carr (1988) reports similar levels with a correlation of 0.9 between IQs measured in the early years and those at 21 years and good prediction for around $80 \%$ of the sample. She confirmed a rise in mental ability scores in the later teenage and early adult years except for the young people with Down syndrome who were most severely disabled.

\section{Attainments:}

Academic attainments( reading, writing, number skills) and self-sufficiency scores have steadily increased over the years for over $90 \%$ of the children. The most powerful predictor of progress has been the child's mental ability score accounting for around $60 \%$ of the variance for academic attainments and 40 to $50 \%$ for self-sufficiency scores.

For academic attainments greater progress was consistently and independently found for those children attending mainstream schools and who had high attentional-low distractibility scores. In 1986 we also found girls to have higher attainments than boys but this was reducing in significance by 1991 . However girls were found to be less distractible than boys. In 1986 we found that children, and more likely boys, of fathers with low locus of control scores made less progress. Thus fathers who feel they may not be able to exert much influence on events may be less inclined to become actively engaged in the child's education or have different aspirations. In 1991 more progress was found for children whose mothers used more practical and problem solving coping strategies to deal with child-related problems.

An indirect influence was found for occupation and educational level. Children of non-manual and higher educated parents were more likely to be placed in mainstream schools from the early years. We found that about half of the cohort children went to a mainstream preschool setting. This was significantly more than a comparison group who had no early intervention support at that time. However the effect was due to more lower educated manual occupation families seeking mainstream school from our cohort. Thus our supportive intervention appeared to help these families to be more aware and assertive. By the teenage years only $10 \%$ of the cohort remained in mainstream school and $90 \%$ of these children resided in non-manual families.

We also found that the main factors related to attendance at mainstream school was mental ability and low distractibility scores. Yet of the children in special schools $15 \%$ had similar levels of ability and $63 \%$ similar levels of attention, and although not statistically significant, more of this group came from manual families. Thus one can speculate that families attitudes towards education, and strategies and skills for dealing with professionals are directly influential on educational placement and thus have an effect on academic attainment.

Self-sufficiency scores are more influenced by family factors than academic attainment. In 1986 we found that once we controlled for mental age, higher self-sufficiency scores were associated with children whose mothers used practical and problem solving coping strategies and lower for those who tended to use wishful thinking. Children who had fewer behaviour problems and were less excitable also gained higher scores. However the effect of mothers style of coping was still significant even for children with difficult temperaments and behaviour.

Environmental influences appear to have a greater impact on the more able children. For example, the fifteen children with mental ages under 32 months in 1986 made half the progress in self-sufficiency than the rest of the sample by 1991. Furthermore mental age only accounted for $21 \%$ of 
the variance on self-sufficiency progress for the $85 \%$ more advanced children compared to $44 \%$ for the whole sample.

Thus, for the majority of children, as they got older the link between cognitive ability and development of life skills became weaker and the influence of family factors correspondingly stronger. In other words, although their cognitive ability imposes limitations on their intellectual achievements, by the time they reach mid to late childhood (with mental ages over 3-4 years) most have the ability to learn a wide range of life skills and will do so when supported by their family and given applicable educational opportunities.

\section{Behaviour problems}

The level of behaviour and management problems decreased over the years. However most of the children who demonstrated persistent behaviour problems from early/mid-childhood still had problems in the teenage years and need high levels of supervision. Up to the late childhood years the children rated as having behaviour problems were more likely to have low mental abilities, high excitability scores, a higher incidence of respiratory infections and low self-sufficiency scores. As noted earlier, when these factors were controlled for, this group also had poorer scores on family cohesion and parent-child relationships, inadequate housing - which reflected financial problems, low social support for parents and unemployment in fathers, mothers using passive coping strategies and those with high neuroticism scores and finally strain from current life events. It is difficult to determine cause and effect in these factors but parent coping styles, financial problems and recurrent child health are likely to effect the management style and interrelationships in the families. They are also reasonable targets for intervention. By 1991 the main predictor of behaviour problems was the ratings in 1986. This suggests that the time for preventative interventions with these families is in the early years.

\section{Social life}

Social life was measured in terms of the children's contact with organised activities e.g. clubs, teams and informal activities e.g. contacts with friends, other people, going on family outings. Although higher overall scores were more likely for the more able children with fewer behaviour problems several family characteristics were far more influential on the type of social life they had. Thus children in families with an active-recreational orientation, younger mothers and more siblings had a wider social life.

These two aspects, organizational contacts and informal contacts, were not necessarily related. Some children had no friends but attended clubs and others had many informal contacts but did not attend organised activities. They were also predicted by different factors. The children with higher levels of informal contacts had younger mothers who used practical coping strategies and did not have financial problems. Children who attended no organised activities were from families with poor marital relationships and fathers with personality problems and stress. In contrast if the child attended a mainstream school they were more likely to engage in a wider range of social activities.

Thus the results identify many environmental factors related to family functioning which have direct impact on the development, behaviour and social life of the child with Down syndrome.

\section{Conclusions}

The overall impression of the families and children with Down syndrome is one of normality. The factors that influence their well being and that of the child are largely the same as those influencing any child and family. The research has emphasised the wide range of individual differences between and within the families and between the children themselves. Consequently generalised statements and assumptions based on the fact that Down syndrome is present should be avoided.

It cannot be assumed that the family or individual members are 'at risk' for psychological problems just because one member has Down syndrome. We found that the majority of families (60-70\%) in the cohort were harmonious with high levels of family cohesion and perceived satisfaction with life and relatively normal levels of stress. They had adapted positively to their child with Down syndrome and report no persistent negative psychological effects on their lives or their other children. In fact they were more likely to feel the child had positively contributed to the family.

I do not wish to minimise the problems these families face. They do experience considerable trauma following the birth and, in their role as parents or relatives of a child with a major disability, have to develop new knowledge and skills and reconstruct their ideas about themselves, their values and aspirations. They often face a society with little understanding and much prejudice. They have to learn to deal with a wide range of professionals and agencies and develop assertive negotiating skills in order to obtain the best resources for their child. They also have to develop practical problem solving strategies and maintain a positive expectant attitude for their child despite the many set-backs, discouragement and slow progress. The fact that so many families cope well is a testimony to their commitment to their child, and their adaptability and strengths, rather than a lack of problems.

They do need accurate information and quality support from services about their child's needs and available services. They need this at critical points in the life-cycle of their child. Certainly in the first months, at the time they select preschool and schools, transitions from childhood to puberty, teenager to young adult, school to college and independent living.

About a third of the families experience difficulties reflected in higher stress and lower satisfaction with life. This was associated with the child characteristics of lower mental ability, behaviour problems, excitable temperament and recurring infections. It was also associated with a cluster of family characteristics e.g. lower levels of utilitarian resources associated with money, housing and employment; lower levels of social support, health problems of parents, and psychological resources such as personality and use of ineffectual coping strategies. All of these factors were found to influence the development and behaviour of the children. They also mediated the levels of stress and satisfaction with life experienced by the parents. Several of these factors are likely to be influenced by intervention.

Of importance was the finding that the best predictor of any measure e.g. stress in the parent, mental ability, selfsufficiency, behaviour problems in the child was the score on the same measure in the previous study 5 years and 9 years earlier. This strongly suggests the need for intervention in the earlier years. 
The research clearly indicates that such intervention should be focused on the family as a unit and not the child or merely the pathology of the child. Generalised programmes of therapy and training which aim to counteract the potential development delay or deficits associated with the child's intellectual disability have not proved to be that effective. This is not surprising given the vast amount of individual differences in the children with Down syndrome and their families. Hence programmes which are automatically applied to all children with Down syndrome are simplistic and not efficient.

My approach is to enter into a partnership relationship with the family in which I explain much of the above research and the model I use to assess their needs. I start by exploring the likely demands on the family resources of the child, relate this to the resources they have available and their strategies of coping. The three sources of demand are:

1) the caretaking demands - these concern the level of personal self-sufficiency in the child (e.g. feeding, dressing bathing, toileting), ill health, mobility. The extent to which the family cope with such demands depends largely on their utilitarian resources, practical social support and health/ energy resources. Thus the needs will relate to finance, housing, transport, laundry, home help, respite care, special diets, labour saving equipment etc. In some families these demands will be influenced by belief systems e.g. the extent to which they encourage self-sufficiency in the child and practical problem solving ability in seeking help and advice.

2) supervisory demands - such as length of time the child can be left alone, whether the child can be trusted in the home, with friends or when out on excursions. These are related to the child's behaviour and ease of management. They are more frequently associated with psychological resources underlying parental values about child behaviour and their ability to apply appropriate and consistent management procedures. However they also encompass social support, housing, and health. Thus the family needs include respite care, professional help with development and applying behavioural management skills. Often, it is essential to consider parental attitudes and their beliefs that they can be effective. Thus programmes supporting their confidence in their parenting skills are important.

3) affective demands - some parents experience low feelings of fulfillment in their parental role. They find it difficult to have positive feelings towards the child. This is sometimes due to the lack of affective behaviours and responses from the child and/or the child not fulfilling the parents hopes and expectations of a child. Such feelings are very common following the disclosure of the diagnosis. At this time the family needs supportive counseling and help in learning how to observe their child and understand and interpret the child's behaviour and development. They may also need to reflect on their feelings about disability and their changed role and expectations of parenthood. These can change and fluctuate as the child grows and the emerging person is observed. They can change as a result of other family factors and changed circumstances. The adaptation of family members (mothers, fathers, siblings, grandparents or significant others) is individual. Support therefore, must be focused on their individual needs but nested within a detailed understanding of their family based upon a careful assessment of resources and the coping mechanisms adopted by members when faced with problems.
We will only be able to predict the full potential of people with Down syndrome when they and their families have access to this type of support at key points in their life-cycle.

\section{References}

Breslau,N., Weitzman,M. \& Messminger,K. (1981). Psychological functioning of siblings of disabled children. Pediatrics, 63, 616-627.

Byrne,E.A. \& Cunningham,C.C.(1985). The effects of mentally handicapped children on families: A conceptual review. Journal of Child Psychology and Psychiatry, 26, 847864.

Byrne, E.A., Cunningham, C.C. \& Sloper, P. (1988). Families and their Children with Down's syndrome: One Feature in Common. London: Routledge.

Carr, J. (1988). Six weeks to twenty-one years: A longitudinal study of children with Down's syndrome and their families. Journal of Child Psychology and Psychiatry, 29, 407-431.

Carr, J. \& Hewett, S. (1982) Children with Down syndrome growing up. Association of Child Psychology and Psychiatry News, 4, 10-13

Cunningham,C.C. (1985). Training and education approaches for parents of children with special needs. British Journal of Medical Psychology, 58, 285-305.

Cunningham,C.C. (1987) Early Intervention in Down's syndrome. In G. Hosking and G. Murphy (Eds) Prevention of mental handicap: A World View. London: Royal Society of Medicine Services.

Cunningham,C.C, \& Davis,H. (1985). Working with Parents: frameworks for collaboration. London: Open University Press.

Cuskelly,M. \& Dodds,M (1992). Behaviour problems in children with Down's syndrome and their siblings. Journal of Child Psychology and Psychiatry, 33, 749-761.

Cuskelly,M. \& Gunn,P. (1993). Maternal reports of behaviour of siblings with children with Down syndrome. American Journal on Mental Retardation, 97, 521-529

Folkman,S. \& Lazarus,R.S. (1985). If it changes it must be a process: a study of emotion and coping during three stages of a college examination. Journal of Personality and Social Psychology, 48, 150-170.

Gath,A. (1973). The school age siblings of mongol children. British Journal of Psychiatry, 123, 161-167.

Gath,A. \& Gumley,D. (1987). Retarded children and their siblings. Journal of Child Psychology and Psychiatry, 28, 715730.

Gibbs,M.V. (1984). The applicability of temperament scales to a British sample of non-handicapped and Down's syndrome children Unpublished PhD thesis, University of Manchester.

Gibson,D. \& Field,D. (1984). Early stimulation programs for Down's syndrome: An effectiveness inventory. In W. Wolraich \& D. Routh (eds) Advances in developmental and behavioural pediatrics. (Vol. 5, 331-372) Greenwich, CT:JAI Press.

Holahan,C.J. \& Moos,R.H. (1986). Personality, coping and family resources in stress resistance. A longitudinal study. Journal of Personality and Social Psychology, 51, 389-395. Kirkham,M.A. (1993). Two-year follow-up of skills training with mothers of children with disabilities. American Journal of Mental Retardation, 5, 509-520.

Knussen,C., Sloper, P., Cunningham,C.C. \& Turner,S. (1992). The use of the Ways of Coping (Revised) questionnaire with parents of children with Down syndrome. Psychological Medicine, 22, 775-786.

Knussen,C. and Sloper,P. (1992). Stress in families of 
children with disability: A review of risk and resistance factors. Journal of Mental Health, 1, 241-256.

Lobato,D., Barbour,L., Hall,L.J. \& Miller, (1987). Psychological characteristics of pre-school siblings of handicapped and non-handicapped children. Journal of Abnormal Child Psychology, 15, 329-388.

McHale,S.M. \& Gamble,W.C. (1989). Sibling relationships of children with disabled and nondisabled brothers and sisters. Developmental Psychology, 25, 421-429.

Mink,I.T., Nihira,E., \& Meyers,C.E. (1983). Taxonomy of family life styles: In Homes with TMR children. American Journal of Mental Deficiency, 87, 484-497

Moos,R.H. \& Moos,B.E. (1981). Family Environment Scale: Manual. Palo Alto, CA: Consulting-Psychologist Press.

Quine,L. \& Pahl,J. (1989). Stress and Coping in Families Caring for a Child with Severe Mental Handicaps: A Longitudinal Study. Final Report. University of Kent: Institute of Social and Applied Psychology and Centre for Health Service Studies.

Rutter,M. (1989) Pathways from childhood to adult life. Journal of Child Psychology and Psychiatry, 30, 23-51.

Shonkoff,J.P., Hauser-Cram,P., Krauss,M.W. \& Upshur,C.C. (1992). Development of infants with disabilities and their families: Implications for theory and service delivery. Monographs of the Society for Research in Child Development, 57, (6, Serial No. 230).

Sloper,P. \& Turner,S. (1993). Risk and resilience factors in the adaptation of parents of children with severe physical disability. Journal of Child Psychology and Psychiatry, 34, 167-158.

Sloper,P. \& Turner,S. (1994). Families of Teenagers with Down's syndrome: Parent, Child and Sibling Adaptation. Final Report to ESRC; Hester Adrian Research Centre, University of Manchester.

Zetlin,S., Williamson,G.G. \& Rosenblatt,W.P. (1887). The coping with stress model: A counseling approach for families with a handicapped child. Journal of Counseling and Development, 65, 443-447.

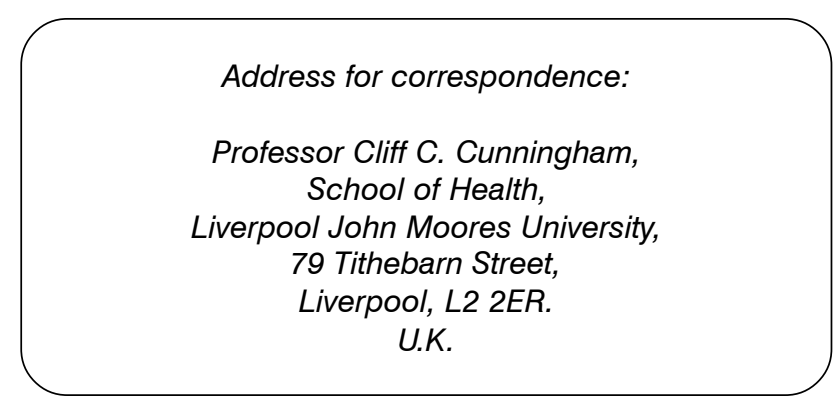

